\title{
INFLUENCE OF DIE ANGLES ON THE MICROHARDNESS OF ALUMINUM ALLOY PROCESSED BY EQUAL CHANNEL ANGULAR PRESSING
}

\author{
Ali A. Aljobouri ${ }^{1}$ And Nurulakmal Mod. Sharif ${ }^{2}$ \\ ${ }^{1}$ Faculty of Arts and Sciences, Alabiar Branch, Univ. of Garyounis, Benghazi, Libya. \\ ${ }^{2}$ School of Materials and Mineral Resources Engineering USM, 14300, Nibong Tebal, \\ Penang, Malaysia.
}

\begin{abstract}
The die geometry has a massive effect on the plastic deformation behavior during pressing of material processed by equal channel angular pressing (ECAP) method; subsequently the properties of the processed material are strongly dependent on the die design. Two categories of designed and manufactured dies are used for equal channel angular pressing, a $120^{\circ}$ sharp angle $\left(\Psi=0^{\circ}\right)$ and a $90^{\circ}$ round-cornered $\left(\Psi=20^{\circ}\right)$ dies. This produce strain per pass through both dies of $\sim 0.7$ and $\sim 1.05$ respectively. The microhardness is developed in $\mathrm{Al}-\mathrm{Si}$ alloy during ECAP using route $\mathrm{B}_{\mathrm{C}}$. The microhardness is increased by a factor of $>1.5$ after only 1 pressing for both dies. The microhardness increases slightly up to 8 passes, to increase by a factor of $\sim 2.6$ through the $120^{\circ}$ sharp angle die, while it is increased by a factor of $\sim 3$ after 8 passes by using the $90^{\circ}$ roundcornered die, compared to the microhardness of the cast workpiece. In addition, the microhardness values are essentially identical across each ECA pressed workpiece on both $\mathrm{X}$ and $\mathrm{Y}$ planes.
\end{abstract}

KEYWORDS: ECAP, Al alloy, Microhardness, Mmicrostructure

\section{INTRODUCTION}

Severe plastic deformation methods have been the subject of intensive investigations in recent years [1]. Extremely high amount of deformation can be introduced by several different ways such as compressed torsion [2], cyclic extrusion compression [3], high pressure torsion (HPT) [4], accumulative rolling banding process (ARB)[5], and equal channel angular pressing(ECAP) [6,7]. The latter process, which is invented by Segal et al. [8], is one of the most promising and interesting ways due to its capability of producing large, fully dense samples containing ultrafine (or nanometer scale) grain size of various metals and their alloys by repeating the process while maintaining the original cross section of the workpiece.

Deformation in ECAP occurs at the shear plane, which is lying at the intersection of the two equal cross-sectional channels of the die, as shown in Fig. 1, where $\Phi$ is the internal angle between the two intersecting channels, and $\Psi$ is the angle defining the outer arc of curvature at the point of intersection of the two channels [9]. 


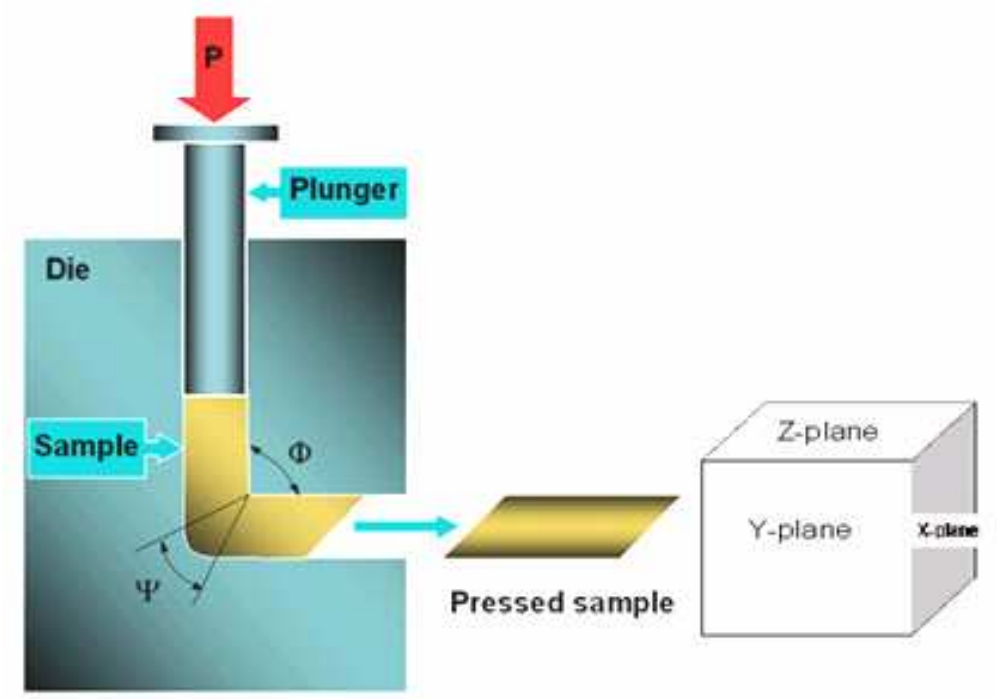

Fig. 1: Angles for equal channel angular pressing and ECAPed workpiece.

As the material crosses the intersection of the channel, it experiences a shear deformation that induces a shear strain. Subsequently, the strain $\varepsilon$, after one cycle is

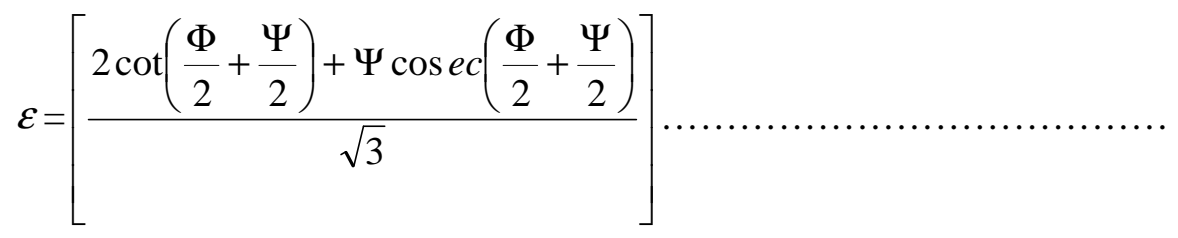

Since in each passage through the die the same strain is accumulated, the following equation represents a more general relationship allowing one to calculate the strain value of the workpiece during ECAP for an $\mathrm{N}$ number of passes.

$$
\varepsilon_{\mathrm{N}}=\mathrm{N}\left[\frac{2 \cot \left(\frac{\Phi}{2}+\frac{\Psi}{2}\right)+\Psi \operatorname{cosec}\left(\frac{\Phi}{2}+\frac{\Psi}{2}\right)}{\sqrt{3}}\right]
$$

According to equation (2), the magnitude of the equivalent strain depends upon the values of $\Phi$ and $\Psi$ angles, where it decreases with the increase of both angles. The equivalent strain during ECAP can decrease from the maximum of 1.15 at minimum value of $\Psi=0^{0}$, to the minimum of 0.907 at the maximum value of $\Psi=90^{\circ}$, when the channel angle is fixed as $\Phi=90^{\circ}$. Nakashima and co-workers [10] processed high purity aluminum $(99.99 \%)$ at room temperature using route $\mathrm{B}_{\mathrm{C}}$, with the $\Psi$ angle fixed to $20^{\circ}$, and with internal channels angles $(\Phi)$ of $90^{\circ}, 112.5^{\circ}, 135^{\circ}$ and $157.5^{\circ}$, producing a strain of 1.05, $0.71,0.47$ and 0.23 per pass, respectively. Therefore, the channel angle $\Phi$ has more influence on the strain generated during ECAP than the die corner angle $\Psi$ [11-13]. 
Since the material emerges from the die without any change in the cross sectional area, it is possible to rotate the workpiece around its longitudinal axis between consecutive passes, creating different ECAP routes. It is possible to define four distinct processing routes $\mathrm{A}, \mathrm{B}_{\mathrm{A}}, \mathrm{B}_{\mathrm{C}}$ and $\mathrm{C}$, which are classified by how the workpiece is rotated with respect to the die for each subsequent pass.

Route A: In this route the workpiece is not rotated between consecutive pressings.

Route B: Routes $\mathrm{B}_{\mathrm{A}}$ and $\mathrm{B}_{\mathrm{C}}$ where the subsequent rotations are made in the sequence of $\left(90^{\circ}, 0^{0}, 90^{\circ}, 0^{\circ}\right)$ or $\left( \pm 90^{\circ}\right)$ and $\left(90^{\circ}, 180^{\circ}, 270^{\circ}, 360^{\circ}\right)$ or $\left(+90^{\circ}\right)$, respectively. In other words, in route $\mathrm{B}$ the workpiece is rotated by $90^{\circ}$ between each pressing, where route $\mathrm{B}_{\mathrm{A}}$ denotes rotations in alternate directions between each two consecutive pressing, and route $B_{C}$ denotes rotations in the same direction between each two consecutive pressing.

Route C: denotes a rotation of $180^{\circ}$ between each two consecutive pressing.

Table 1 summarizes these four fundamental ECAP routes. Most researchers have reported that route $B_{C}$ leads to an enhanced rate of grain refinement and a more isotropic equiaxed submicron grain structure, compared to other deformation routes with a $90^{\circ}$ die angle [14-16].

Table 1: Rotation angles and directions for four fundamental processing routes [17].

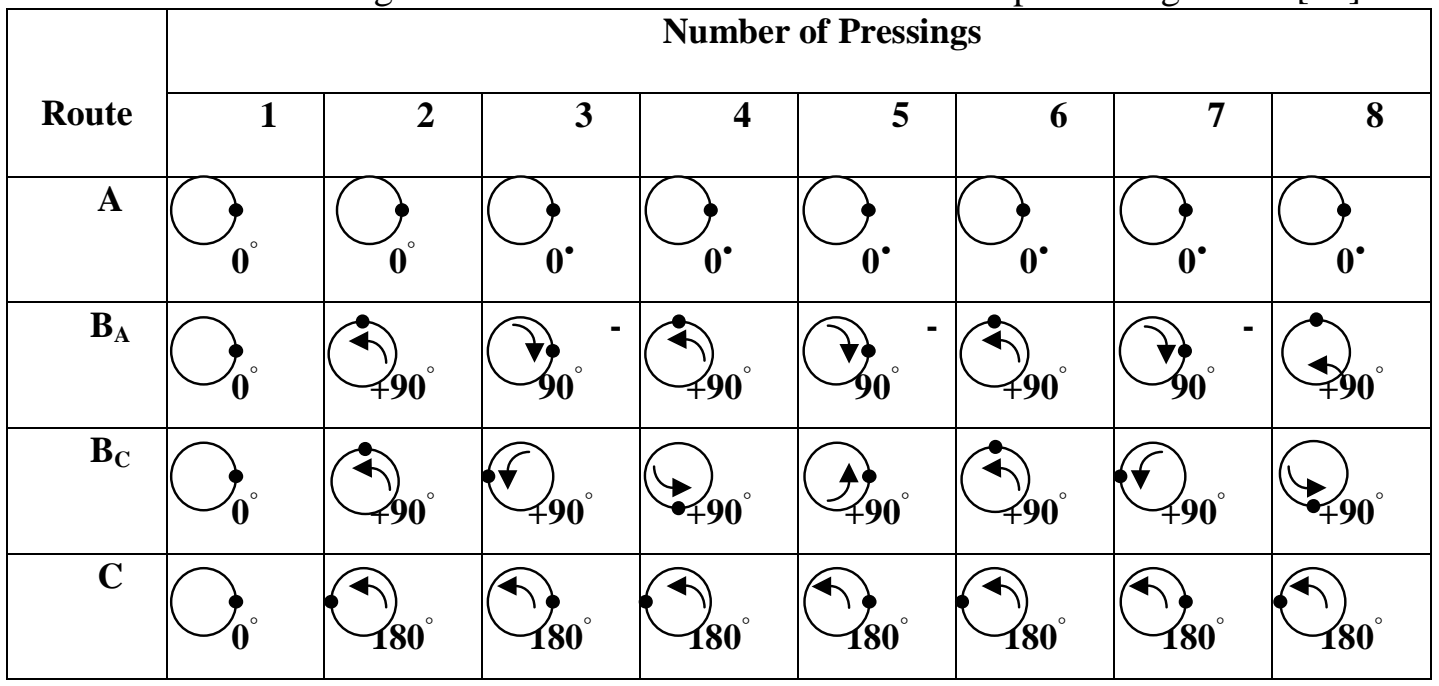

ECAP can be used to produce large amounts of porosity free and impurity free bulk of ultrafine grained (UFG) materials with high-angle grain boundaries (HAGBs) [18].

The hardness of a material is generally related to the grain size through a Hall-Petch equation [19] of the form

$$
\mathrm{H} v=\mathrm{H}_{0}+\mathrm{k}_{\mathrm{H}} \mathrm{d}^{-1 / 2}
$$


where $\mathrm{H}_{0}$ and $\mathrm{k}_{\mathrm{H}}$ are appropriate constants associated with the hardness measurements. This equation established that the hardness or the strength of the material increases with decreasing grain size.

In the present study, ECAP with different die angles was used to achieve two objectives. First, to investigate the feasibility of obtaining ultrafine grain sizes of Al-Si alloy through the use of ECAP technique at room temperature. Second, to achieve significant increasing in microhardness properties of ECA Pressed Al-Si alloy at room temperature.

\section{METHODS AND EXPERIMENTS}

$\mathrm{X}$-ray fluorescence (XRF) equipment was used to determine the chemical composition of the material. The material used in this study was identify as an aluminum alloy containing 98 wt. \% Al, 1.3 wt. \% Si, 0.3 wt. \% Mg, 0.18 wt. \% Fe, 0.023 wt.\% Cu, 0.019 wt. \% Mn, 0.017 wt. $\% \mathrm{Zn}, 0.014$ wt. \% Ga, and 0.011 wt. \% Ti. The material was subjected to severe plastic deformation using ECAP at room temperature in order to investigate the effect of ECAP on the microhardness properties of this alloy. Each of the ECAP dies designed for this study consisted of two blocks of SKD 11 tool steel, bolted together to give a die with two channels having an equal circular cross-section with the diameter of $10 \mathrm{~mm}$. The two channels of the two dies intersected at the angles $(\Phi)$ of $120^{\circ}$, with $(\Psi)$ of $0^{\circ}$ and $(\Phi)$ of $90^{\circ}$, with $(\Psi)$ of $20^{\circ}$.

Workpieces were prepared by melting Al-Si alloy billets and cast into a circular sand molds $(\phi 15 \mathrm{~mm}$ X $150 \mathrm{~mm})$.The cast ingots were machined by lathe machine with cooling oil to overcome the machining effect. The machined rods with dimensions of $(\phi 10 \mathrm{~mm}$ X $50 \mathrm{~mm}$ ) became suitable for pressing by ECAP facility. Prior to ECAP, the surface of the workpieces was polished using $\mathrm{SiC}$ abrasive papers with grades 100, 230, $400,600,800,1000$ and 1200 to reduce the friction between the workpiece and the die wall.

Universal Testing Machine (UTM) was used to press the workpiece through the dies. The workpiece enters the die through a vertical channel, passes through the shearing plane at the point of intersection of the two parts of the channel, and then emerges from the die through the horizontal or exit channel. Route $\mathrm{B}_{\mathrm{C}}$ is selected in this experiment by rotating the workpiece $90^{\circ}$ in the same sense around its longitudinal axis between each two consecutive passing for the end of producing an equiaxed grain structure with high angle grain boundaries. Many researchers used this route to create a homogeneous ultrafine grained Aluminum alloy [20, 21]. Grease was used as a lubricant in the extrusion for more friction reduction.

The model of the scanning electron microscope (SEM) used in this study was Supra 35VP Field Emission (FE-SEM). The average grain and subgrain sizes was taken from measurements made directly from the SEM photomicrographs using the linear intercept method (at least 5 different places on a sample were measured). 
Following ECAP process, the workpieces were sliced from an X-plane (perpendicular to the longitudinal axis of the pressed workpiece) and a Y-plane (the side-viewed plane parallel to the longitudinal axis of the workpiece) to a thickness of $2 \mathrm{~mm}$ from the middle section of the workpieces after each pass, using a diamond cutter with oil as lubricant. The sectioned samples were cold-mounted using epoxy resin and then they were polished to become suitable for the scanning electron microscope (SEM) as well as for microhardness measurements.

\section{RESULTS AND DISCUSSION}

One of the most important indications of mechanical properties improvement is a microhardness measurement. The microhardness values for the present study were determined using a microhardness tester with pyramidal indenter, and were taken by applying a load of $300 \mathrm{~g}$ for 8 seconds on the $\mathrm{X}$ and $\mathrm{Y}$-planes samples. The spacing between points both in $\mathrm{X}$ and $\mathrm{Y}$-planes was $0.9 \mathrm{~mm}$ as shown in Fig. 2. Twelve separate measurements were taken at a diametric line from the bottom to the top on each workpiece. The Vickers microhardness value was determined by taking the average of the twelve measurements on the workpiece.

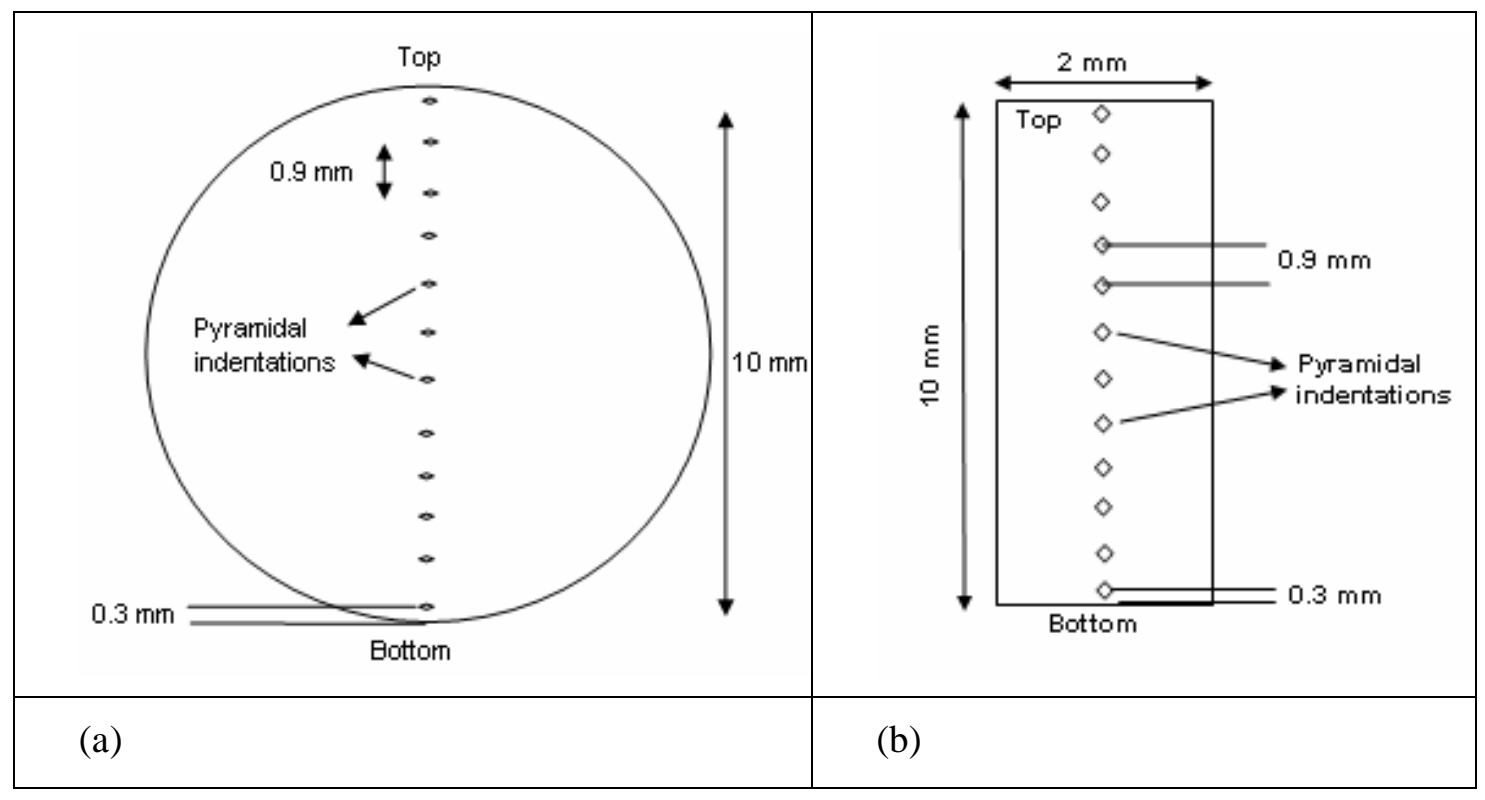

Fig. 2: Sketch of pyramidal Vickers indentations on (a) X-plane, (b) Y-plane.

The microhardness on the X-plane and the Y-plane had the same tendency to increase with the number of passes. The microhardness was increased by a factor of $>1.5$ due to the highly deformed state, after one pass through the die with $\Phi=120^{\circ}$ and $\Psi=0^{0}$, as clearly shown by comparing the indentations sizes in Fig. 3 and Fig. 4. Figure 4 also shows that the microstructure of Al-Si alloy was homogeneous before the ECAP, and that the grains had a size of approximately 60-70 $\mu \mathrm{m}$. Subsequently, the microhardness increased slightly 
up to 8 pressings as shown in Fig. 5. The drastic increase of microhardness after the pressing is due to the reduction in the grain size from $70 \mu \mathrm{m}$ for cast workpiece to $\sim 200$ $\mathrm{nm}$ for ECAPed workpiece after six passes (shown in Fig. 6), as well as by the density increase of dislocation when the number of passes is increased for route $\mathrm{B}_{\mathrm{C}}$ [22].

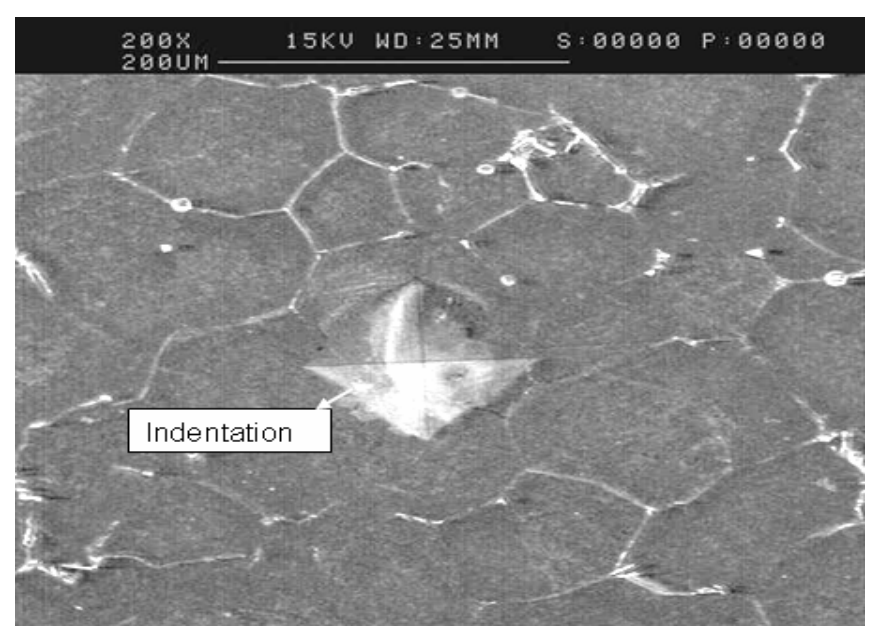

Fig. 3: SEM photomicrograph showing microstructures of the Al-Si alloy as cast (x 200 marker $200 \mu \mathrm{m})$.

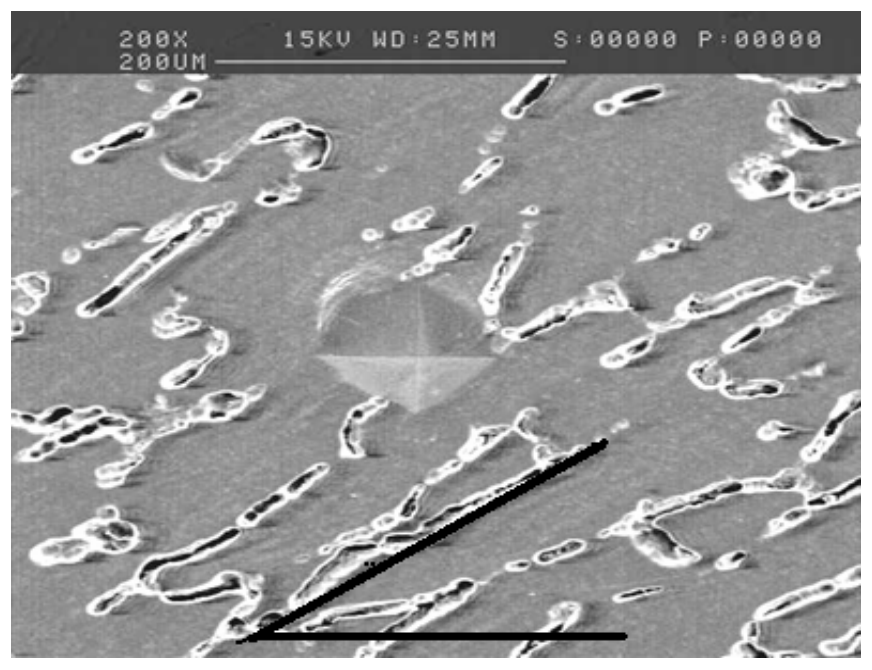

Fig. 4: SEM photomicrograph showing microstructures of the Al-Si alloy after 1 pass on the Y-plane using a die with $\Phi=120^{\circ}$ and $\Psi=0^{0}$ using route $\mathrm{B}_{\mathrm{C}}$. 


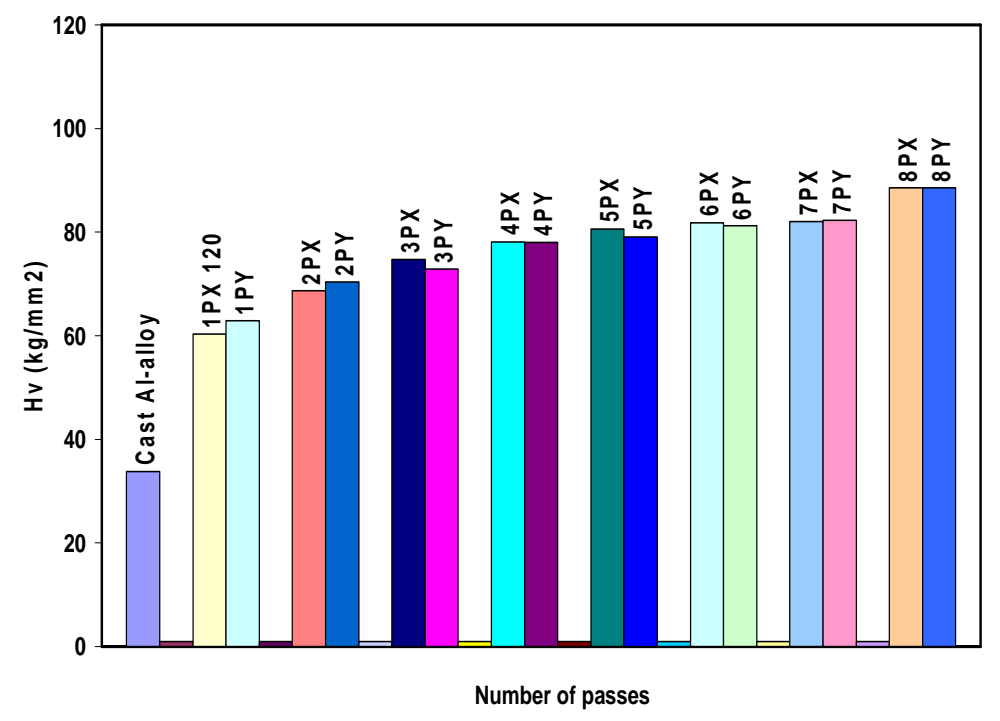

Fig. 5: The average values of Vickers microhardness (Hv) for the cast and ECAPed AlSi workpieces on the $\mathrm{X}$ and $\mathrm{Y}$ planes, showing alongside the number of passes through the die with $\Phi=120^{\circ}$ and $\Psi=0^{0}$. (P: Pass, X: X-plane and Y: Y-plane).

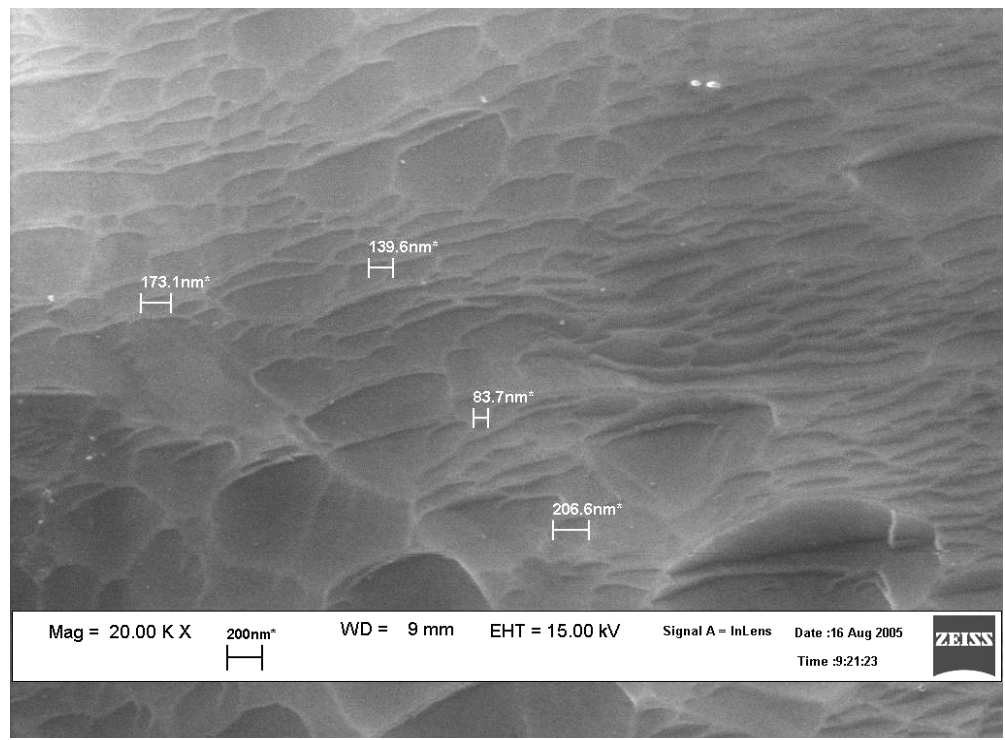

Fig. 6: SEM photomicrograph showing microstructures of the Al-Si alloy pressed through the die with $\Phi=120^{\circ}$ and $\Psi=0^{\circ}$ using route $\mathrm{B}_{\mathrm{C}}$; after 2 passes on the X-plane.

Figures 7 and 8 show that there is no significant difference in microhardness across the cross section of the ECA pressed workpiece on the $\mathrm{X}$ and Y-planes respectively. The individual microhardness measurements are shown in Fig. 9 for the $X$ and Y-planes after four passes through the die. It is apparent from this figure that there is some scatter in the individual datum points. Although all of the individual points lie within a reasonably narrow band, and are consistent with the presence of a reasonable degree of homogeneity 
throughout the workpiece. But there is a little increase of microhardness values at the top surface of the workpiece due to high deformation at the inner angle of the die [23].

Hardness measurements for ECA pressed workpieces made by means of a die with $\Phi=90^{\circ}$ and $\Psi=20^{\circ}$ show that the value of Vickers microhardness is essentially identical across the workpiece on both $\mathrm{X}$ and $\mathrm{Y}$ planes as shown in Fig. 10 and Fig. 11, respectively - despite the lack of a fully homogeneous microstructure revealed by the presence of some elongated grains, as shown in Fig. 12. This shows that the structure yields an equal amount of strain throughout the whole workpiece. This result is in consistent with the results obtained by Chang et al. [24] and Shin et al. [25] on $6061 \mathrm{Al}$ alloys.

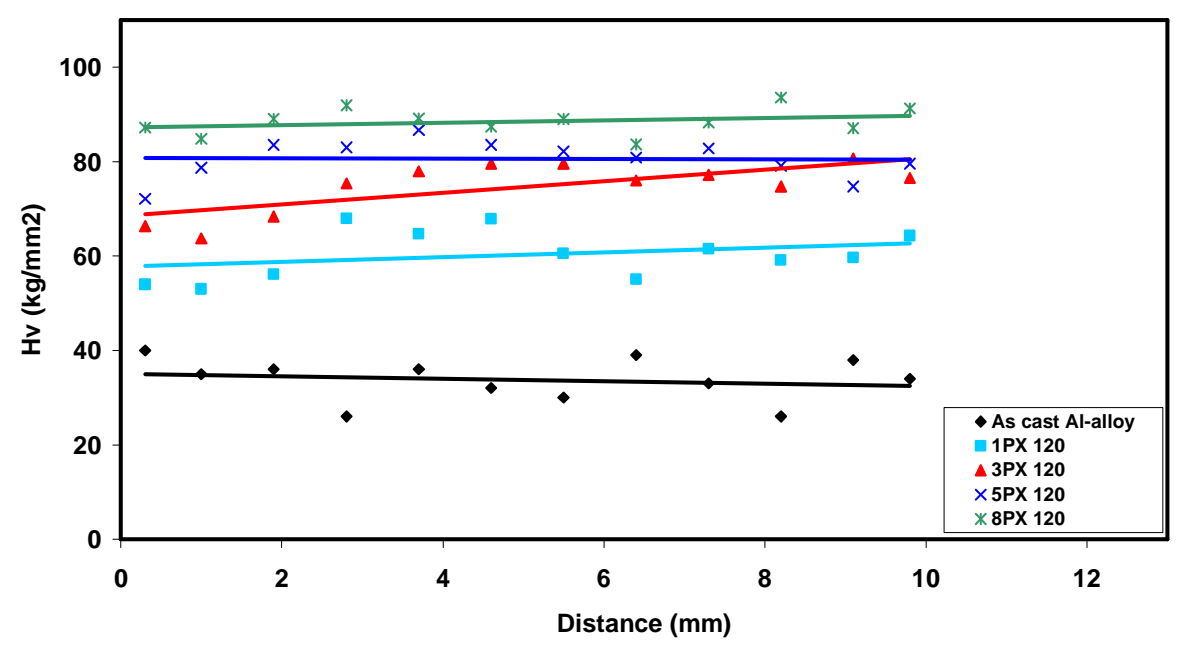

Fig. 7: Vickers microhardness at X-plane for cast Al-Si alloy, 1, 3, 5 and 8 passes through the die with $\Phi=120^{\circ}$ and $\Psi=0^{\circ}$ from the bottom (near to $\Psi$ ) to the top (near to $\Phi)$ of the Workpiece.

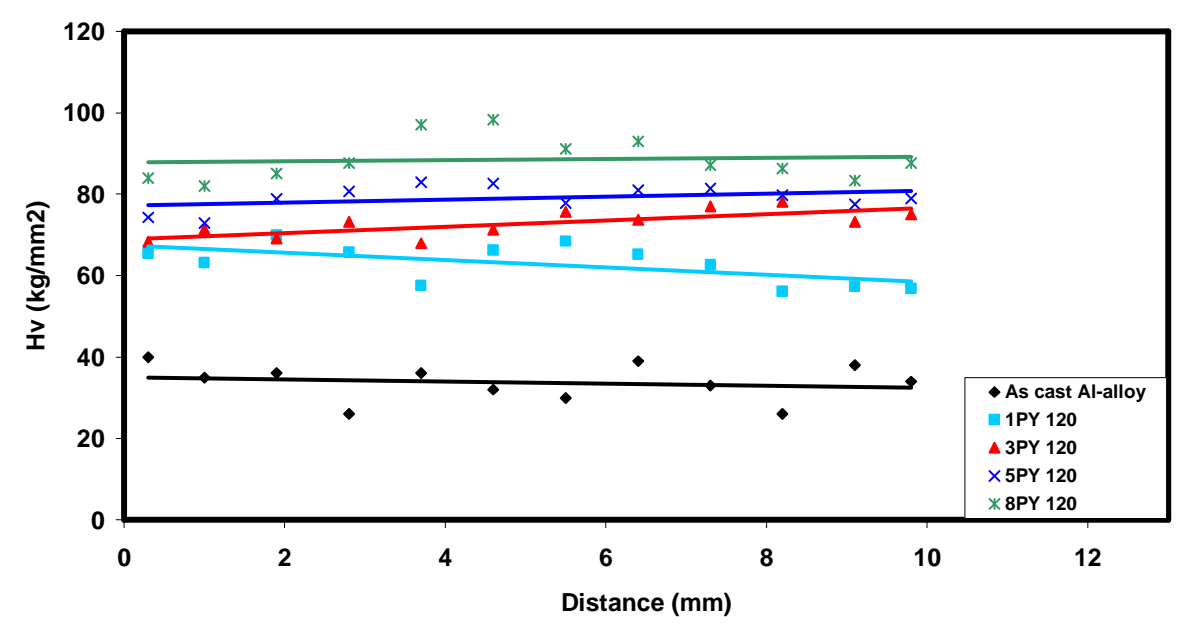

Fig. 8: Vickers microhardness at Y-plane for cast Al-Si alloy, 1, 3, 5 and 8 passes through the die with $\Phi=120^{\circ}$ and $\Psi=0^{\circ}$ from the bottom (near to $\Psi$ ) to the top (near to $\Phi)$ of the Workpiece. 


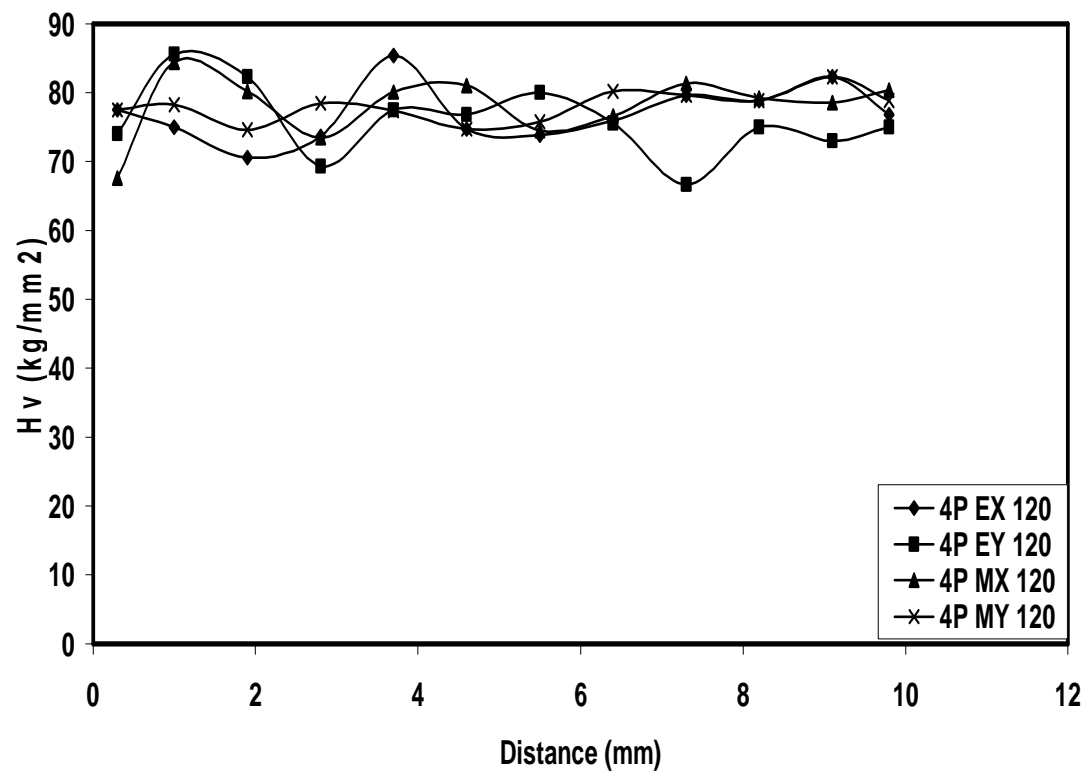

Fig. 9: Vickers microhardness from the bottom to the top of the Al-Si workpiece at two locations for 4 passes through the die with $\Phi=120^{\circ}$ and $\Psi=0^{\circ}$ on the $\mathrm{X}$ and Y planes. (E: end of the workpiece that is in touch with the Plunger) ; ( M: middle of the workpiece); (X: $\mathrm{X}$-plane and Y: Y-plane); (P: pass).

It can be seen that the $\mathrm{Hv}$ values of the workpieces increased significantly during deformation. The average microhardness of the workpieces after six pressings increased almost three times compared to that of the cast workpiece as shown in Fig. 13. According to equation (1) this result is in agreement with the changes in microstructure where the microhardness increases with decreasing grain size. It is easy to noticed the reduction in the grain size from $70 \mu \mathrm{m}$ for cast sample to $\sim 150 \mathrm{~nm}$ in Fig. 12 for ECAPed sample after 7 passes. Another cause for the increase of microhardness is the generation of high dislocation density, which occurred with the shear deformation in the initial grain and the large number of structural defects [26]. A comparison between Fig. 5 and Fig. 13 shows higher values of microhardness in the latter Figure. This is in accordance with the finite element method analysis conducted by Luis Perez et al. [27], where maximum strains and high friction conditions were reached for sharper inner angle. As well as, the dislocation density in the right angle die is higher than that in the obtuse angle die. Which is attributed to the larger strain rate in the right angle die than that in the obtuse angle die [28]. 


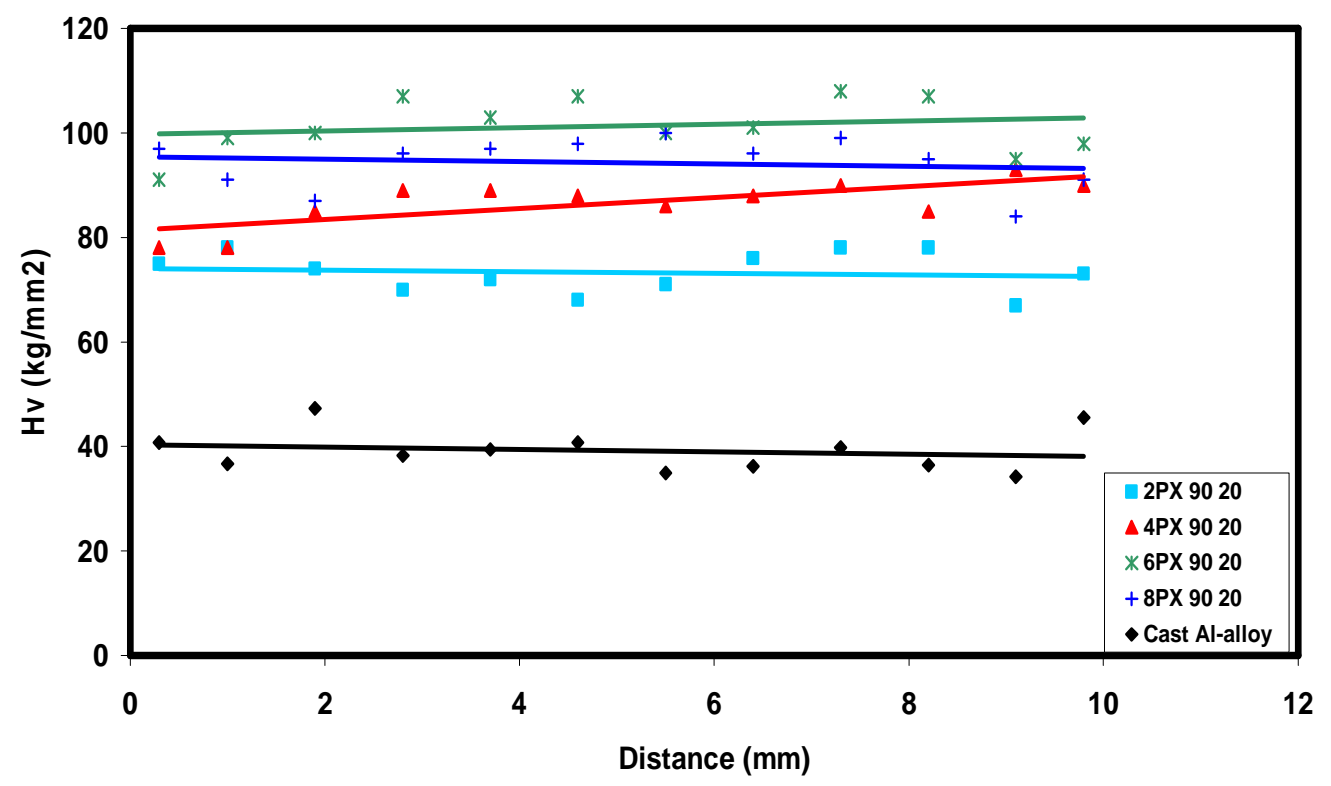

Fig.10: Vickers microhardness (Hv) profiles at X-plane along the transverse distance from the bottom (near to $\Psi$ ) to the top (near to $\Phi$ ) of the cast, 2, 4, 6 and 8 ECAPed AlSi alloy workpieces through the die with $\Phi=90^{\circ}$ and $\Psi=20^{\circ}$.

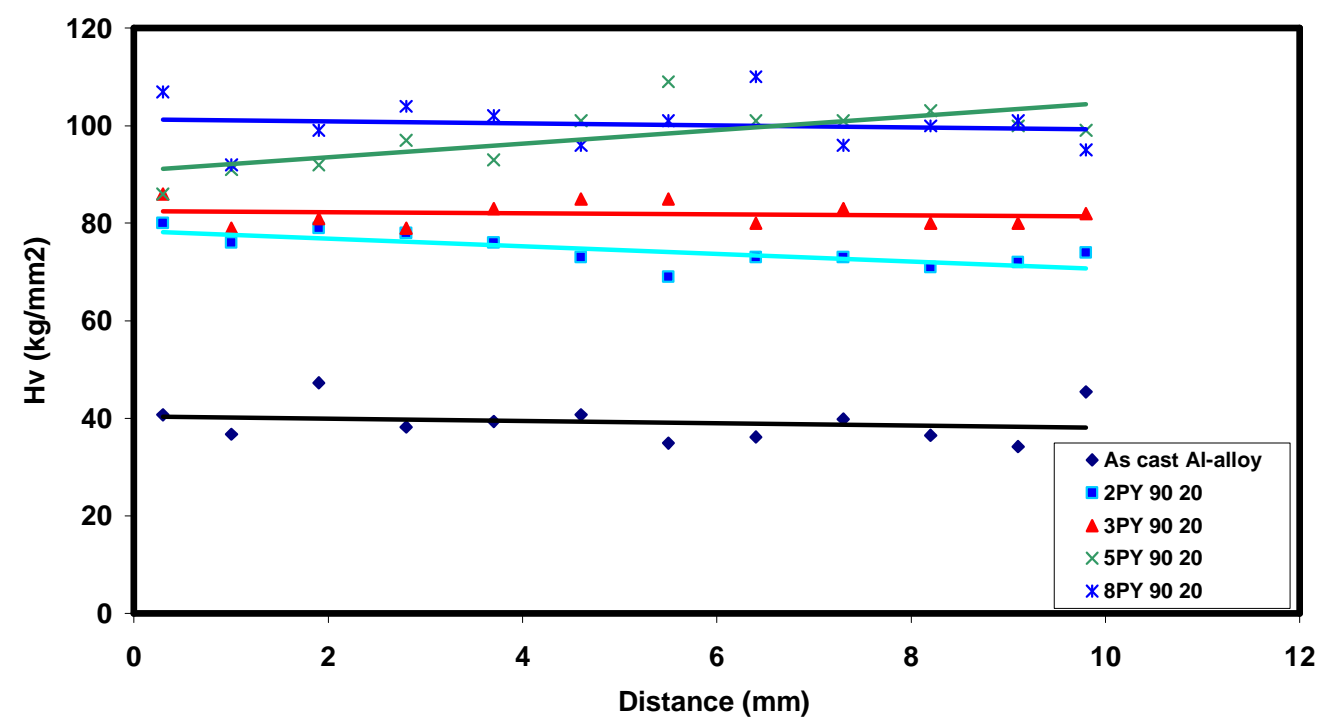

Fig.11: Shows the Vickers microhardness (Hv) profiles at Y-plane along transverse distance from the bottom (near to $\Psi$ ) to the top (near to $\Phi$ ) of the cast, 2, 3, 5 and 8 ECAPed Al-Si alloy workpieces through the die with $\Phi=90^{\circ}$ and $\Psi=20^{\circ}$. 


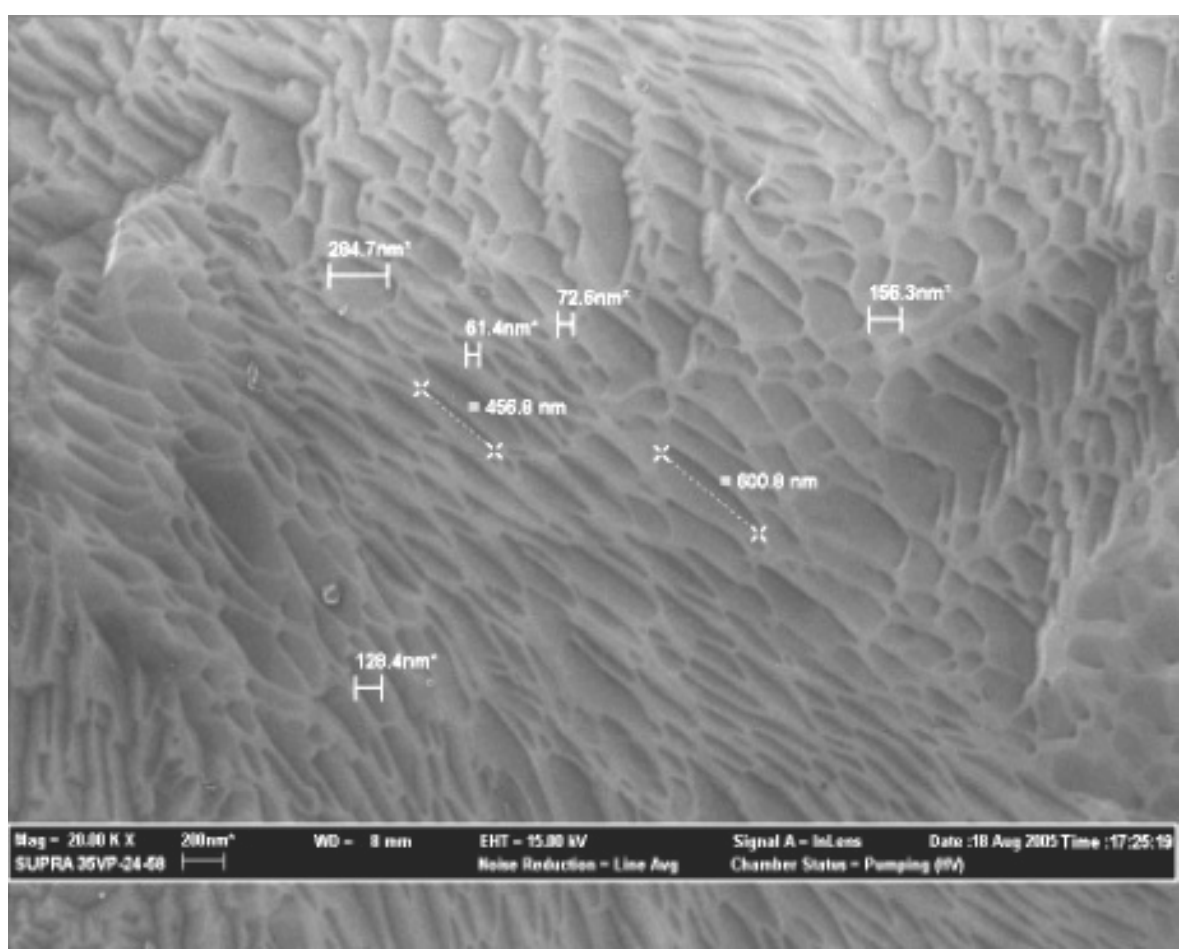

Fig.12: Microstructure of ECA pressed Al-Si alloy after 7 passes through the die with $\Phi=90^{\circ}$ and $\Psi=20^{\circ}$, using route $\mathrm{B}_{\mathrm{C}}$.

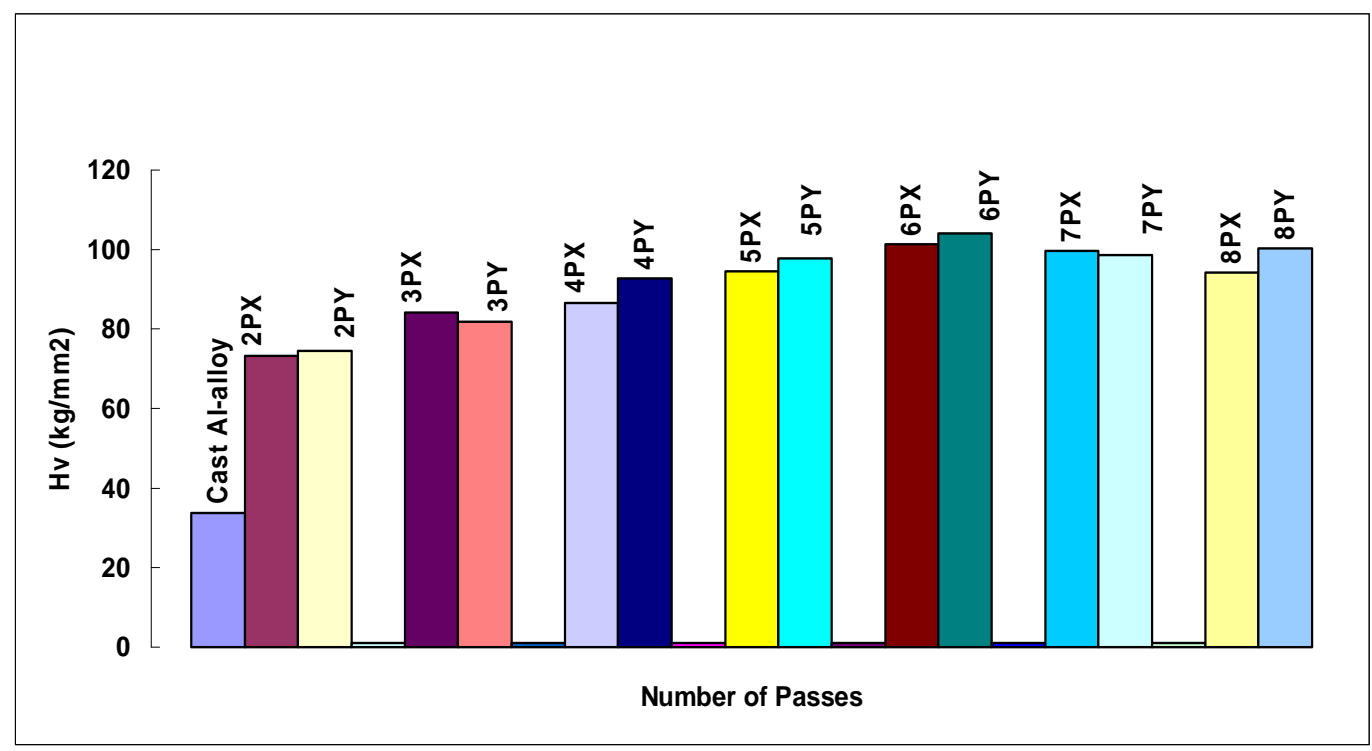

Fig. 13: The average values of Vickers microhardness (Hv) for the cast and ECAPed $\mathrm{Al}-\mathrm{Si}$ workpieces at the $\mathrm{X}$ and $\mathrm{Y}$-planes shown alongside the number of passes through the die with $\Phi=90^{\circ}$ and $\Psi=20^{\circ}$. (P: pass, X: X-plane and Y: Y-plane). 


\section{CONCLUSION}

Significant increase in microhardness is obtained after the first pressing through the ECAP dies. It increases by a factor of $>1.5$ when compared to the microhardness of the cast workpiece. After the first pass, the microhardness increases slightly up to 8 passes in both dies, where it is increases by a factor of $\sim 2.6$ when using the die with $\Phi=120^{\circ}$, and by a factor of $\sim 3$ when the die with $\Phi=90^{\circ}$ is used. Thus, it is well established that the microhardness of ultrafine-grained materials (pressed workpieces) is higher than the microhardness of similar materials with large grain size (cast workpiece). The microhardness has the same tendency to increase at X and Y-planes with the number of passes. No significant difference is noticeable in microhardness across the cross-section of the ECA pressed workpieces on $\mathrm{X}$ and $\mathrm{Y}$ planes.

\section{REFERENCES}

[1] Azushima A., Kopp R., Korhonen A., Yang D.Y., Micari F., Lahoti G.D., Groche P., Yanagimoto J., Tsuji N., Rosochowski A., Yanagida A. (2008), Severe plastic deformation (SPD) processes for metals. CIRP Annals - Manufacturing Technology 57, 716-735.

[2] Valiev R.Z. (1997). Structure and mechanical properties of ultrafine grained metals. Mater. Sci. Eng. A234-236, 59-66.

[3] Korbel A., Richert M., Richert J. (1981) The Effects of Very High Cumulative Deformation on Structure and Mechanical Properties of Aluminium. Proceedings of Second RISO International Symposium on Metallurgy and Material Science, Roskilde, September 14-18, $445-450$.

[4] Lowe T.C. and Valiev R.Z. (2000). Producing nanoscale microstructures through severe plastic deformation. JOM 52, 4, 27.

[5] Lee S.H., Saito Y., Tsujib N., Utsunomiya H., Sakai T., (2002). Role of shear strain in ultragrain refinement by accumulative roll-bonding (ARB) process. Secripta Materialia 46,4,281-285.

[6] Segal V.M. (2002) Severe Plastic Deformation: Simple Shear Versus Pure Shear.Materials. Science and Engineering A 338(1-2):331-344.

[7] Valiev R.Z., Estrin Y., Horita Z., Langdon T.G., Zehetbauer M.J., Zhu Y.T. (2006). Producing Bulk Ultrafine-grained Materials by Severe Plastic Deformation. JOM 58(4):3339.

[8] Segal V. M., Reznikov V.I., Drobyshevkiy A.E. and Kopylov V.I. (1981). Plastic working of metals by simple shear. Russian Metall. 1, 99-105.

[9] Iwahashi, Y., Wang J., Horita Z., Nemoto M. and Langdon T. G., (1996). Principle of equal channel angular pressing of ultra-fine grained materials. Scripta mater. 35, 143-146.

[10] Nakashima K., Horita Z., Nemoto M. and Langdon T. J. (1998). Influence of channel angle on the development of ultrafine grains in ECAP. Acta Mater. 46, 1589-1599.

[11] Prangnell P.B., Harris C., and. Roberts S.M., (1997). Finite element modeling of equal channel angular extrusion. Scripta Mater. 37, 983-989.

[12] Semiatin S.L., Delo D.P., and Shell E.B., (2000). The effect of material properties and tooling design on deformation and fracture during equal channel angular extrusion. Acta Mater. 48, 1841-1851. 
[13] Basavaraj V. P., Chakkingal U., Kumar T.S.P.(2009). Study of channel angle influence on material flow and strain inhomogeneity in equal channel angular pressing using 3D finite element simulation. Journal of materials processing technology 209, 89-95.

[14] Iwahashi Y., Horita Z., Nemoto M. and Langdon T.G. (1997). An investigation of microstructural evolution during ECAP. Acta Metall. Mater, 45, 4733-4741.

[15] Iwahashi Y., Horita Z., Nemoto M. and Langdon T.G. (1998). The process of grain refinement in equal-channel angular pressing. Acta Mater. 46, 3317-3331.

[16] Oh-Ishi K., Horita Z., Furukawa M., Nemoto M., Langdon T.G. (1998). Optimizing the rotation conditions for grain refinement in ECAP. Metall. Mater. Trans. 29A 2011-2013.

[17] Furukawa M., Iwahashi Y., Horita Z., Nemoto M., Langdon T.G., (1998). The shearing characteristics associated with equal-channel angular pressing. Mater. Sci. Eng. A257, 328332.

[18] Sun P.L., Kao P.W., Chang C.P. (2004), High angle boundary formation by grain subdivision in equal channel angular extrusion. Scripta Materialia 51, 565-570.

[19] Furukawa M., Iwahashi Y. Horita Z., Nemoto M., Tsenev N.K., Valiev R.Z. and Langdon T.G. (1997). Structural evolution and the Hall-Petch relationship in an Al-Mg-Li-Zr alloy with ultra-fine grain size. Acta Mater. 45, 4751-4757.

[20] Sabirov I., Estrin Y., Barnett M.R., Timokhina I., Hodgson P.D. (2008). Tensile deformation of an ultrafine-grained aluminum alloy: Micro shear banding and grain boundary sliding. Acta Materialia 56, 10, 2223-2230.

[21] Sabirov I., Barnett M.R., Estrinb Y., and Hodgson P.D. (2009). The effect of strain rate on the deformation mechanisms and the strain rate sensitivity of an ultra-fine-grained $\mathrm{Al}$ alloy. Scripta Materialia 61 (2009) 181-184.

[22] Atef Rebhia, Thabet Makhlouf, Nabil Njaha, Yannick Championb, Jean-Philippe Couziniéb (2009). Characterization of aluminum processed by equal channel angular extrusion: Effect of processing route. Materials Characterization 60, 1489-1495.

[23] Kim H.S., Hong S.I., Seo M.H. (2001). Effects of strain hardenability and strain rate sensitivity on the plastic flow and deformation homogeneity during equal channel angular pressing. J. Mater. Res. 16, 856.

[24] Chang S.Y., Lee K.S, Choi S.H., Shin D.H., (2003). Effect of ECAP on microstructure and mechanical properties of a commercial $6061 \mathrm{Al}$ alloy produced by powder metallurgy. $J$. Alloy and compounds 354, 216-220.

[25] Shin D.H., Park J.J., Kim Y.S. and Park K.T. (2002). Constrain groove pressing and its application to grain refinement of aluminum. Mater. Sci. Eng. A328, 98-103.

[26] Liu Z. Y., Liang G. X., Wang E. D., and Wang Z. R. (1998). The effect of cumulative large plastic strain on the structure and properties of a $\mathrm{Cu}-\mathrm{Zn}$ alloy. Mater. Sci. Eng. A 242, 137140.

[27] Luis Perez C.J., Gonzales P. and Garces Y. (2003). Equal channel angular extrusion in a commercial Al-Mn alloy. J. Mater. Process. Tech. 134-144, 506-511.

[28] Hosseini E., Kazeminezhad M. (2009). The effect of ECAP die shape on nano-structure of materials. Computational Materials Science 44, 962-967 